\title{
Poda de frutificação em cultivares de goiabeira-serrana
}

\author{
Fernando David Sánchez-Mora', Luciano Saifert ${ }^{2}$, Marlise Nara Ciotta ${ }^{3}$, Mateus da Silveira Pasa ${ }^{4}$ e Rubens Onofre Nodari ${ }^{5}$
}

Resumo - O objetivo deste trabalho foi avaliar o efeito da poda nos cultivares comerciais de goiabeira-serrana "Alcântara" e "Nonante" nas safras 2016/17 e 2017/18. Os tratamentos foram sem poda de frutificação (SP) e com poda de frutificação (CP), com três repetições por cultivar. Foram avaliadas as características de planta como o diâmetro do caule, o diâmetro de copa, a altura de planta, o índice de área foliar, o número total de frutos por planta e a frutificação efetiva. Também foram avaliados o diâmetro, o comprimento e o peso total do fruto, o rendimento de polpa (\%), os sólidos solúveis totais, a acidez titulável e o pH. A poda influenciou o diâmetro, o comprimento e o peso dos frutos nos dois cultivares. Na média, o peso foi 73,1 e 65,9g para o cv Nonante, 83,5 e 76,9g no cv Alcântara, nas safras 2016/17 e 2017/18, respectivamente, o que demonstrou a importância da poda de frutificação para a qualidade e a produtividade dos frutos de goiabeira-serrana.

Termos para indexação: Acca sellowiana; produção de frutos; qualidade de frutos.

\section{Fruit pruning in Feijoa varieties}

Abstract - This work aims to evaluate the effect of pruning in the commercial varieties of feijoa "Alcântara" and "Nonante" on the 2016/17 and 2017/18 seasons. The treatments were without pruning (SP) and with pruning (CP), with three replications per cultivar. The plant's traits studied were: diameter of the stem, diameter of the canopy, height of plant, leaf area index, the total number of fruits per plant and fruit set. Also were evaluated the diameter, length and total weight of the fruit, yield of pulp (\%), total soluble solids, titratable acidity and $\mathrm{pH}$. The pruning influenced the diameter, length and weight of the fruits in both cultivars. On average, the weight was 73.1 and $65.9 \mathrm{~g}$ for cv. Nonante, 83.5 and $76.9 \mathrm{~g}$ in cv. Alcântara, in the 2016/17 and $2017 / 18$ harvest, respectively, which showed the importance of fruit pruning for the quality and productivity of feijoa fruits.

Index terms: Acca sellowiana; fruit production; fruit quality.

A goiabeira-serrana [Acca sellowiana (O. Berg) Burret, sin. Feijoa sellowiana (O.Berg) O.Berg], é uma árvore frutífera nativa do sul do Brasil e norte do Uruguai, em geral na forma de arbusto com folhas persistentes, que raramente ultrapassa 5 metros de altura, bastante ramificada, especialmente quando se encontra em campo aberto (DUCROQUET et al., 2000). Embora seja uma fruta com muito potencial para o consumo, carece de conhecimento científico e técnico para que se possa viabilizar economicamente seu cultivo em larga escala.

No sistema de manejo atual para o cultivo, em geral é realizada apenas uma poda leve quando são retirados em média dois ramos mais vigorosos e enve-
Ihecidos no interior da planta. Além disso, é realizado um desponte em ramos nas entrelinhas ou entre as plantas que possam estar em crescimento desproporcional ou dificultando a passagem de equipamentos para outras práticas de manejo. Porém, em espécies frutíferas em geral, a poda de frutificação é uma das práticas culturais fundamentais para a produção de frutos de elevado padrão de qualidade (RAMOS et al., 2011). No caso do araçazeiro (Psidium cattleyanum), também espécie nativa, a produção de estruturas reprodutivas foi favorecida com a prática da poda realizada com aproximadamente 40 dias após a ocorrência das últimas geadas da estação (NETO et al., 2018). Na Colômbia, foi demonstrado que em plantas de goiabeira-serrana com boa fertilidade (botões florais, flores e frutos), as novas brotações, que são estimuladas com a poda, encontram-se acompanhadas de uma boa quantidade de novos botões florais, enquanto nas plantas que têm baixa fertilidade, o estímulo de novas florações com a poda foi pequeno ou insignificante (QUINTERO, 2003). No sul do Brasil, por estar ainda em expansão o cultivo da goiabeira-serrana em termos comerciais, são escassas as informações disponíveis sobre poda e condução, especialmente para os cultivares brasileiros. Assim, o objetivo deste trabalho foi avaliar o efeito da poda de frutificação em dois cultivares comerciais em São Joaquim, Santa Catarina (SC).

$\mathrm{O}$ experimento foi realizado pela

Recebido em 25/4/2019. Aceito para publicação em 12/12/2019.

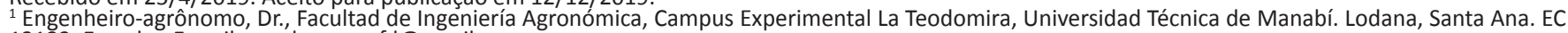

13132, Ecuador. E-mail: sanchezmorafd@gmail.com.

2 Engenheiro-agrônomo, MSc. RGV/UFSC. Rod Admar Gonzaga, 1346, 88.034-000, Florianópolis, SC, e-mail: lucianosaifert@hotmail.com.

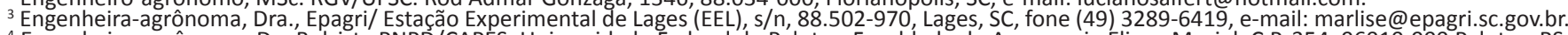

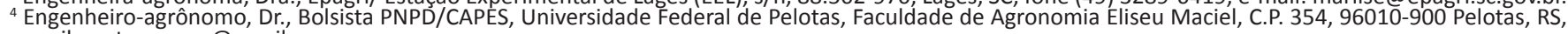
e-mail: mateus.pasa@gmail.com.

${ }^{5}$ Engenheiro-agrônomo, Dr., Rod. Admar Gonzaga, 88.034-000, Florianópolis, SC, e-mail: rubens.nodari@ufsc.br. 
Empresa de Pesquisa Agropecuária e Extensão Rural de Santa Catarina (Epagri), na Estação Experimental de São Joaquim, durante as safras 2016/17 e 2017/18. Foram utilizadas plantas adultas e em produção dos cultivares comerciais de goiabeira-serrana "Alcântara" e "Nonante", implantadas no ano 1996. Estas plantas, antes da implantação do experimento, foram podadas como forma de diminuir altura, sendo retirados no máximo os dois ramos mais grossos anualmente. Os tratamentos foram: sem poda de frutificação (SP) e com poda de frutificação (CP), sendo utilizadas três repetições para cada tratamento (uma planta por repetição). $\mathrm{Na}$ referida poda, primeiramente foi contabilizado o número de ramos principais da planta, dos quais foram removidos aproximadamente $40 \%$ dos ramos (mediante observação visual), deixando-se apenas aqueles com maior potencial produtivo (menos envelhecidos). Além disso, foram retirados de dois a três ramos maiores (diâmetro de 2,5-5cm) da porção central da planta. A poda foi realizada no mês de junho de cada ano. Após a poda, no mês de agosto de cada ano, foram avaliadas as características das plantas: o diâmetro do caule (CAU $\mathrm{cm}$ ), medido a $40 \mathrm{~cm}$ do solo; o diâmetro de copa (COP - cm), e a altura de planta (ALT - cm); o índice de área foliar (IAF), estimado com a utilização de ceptômetro, mediante 10 leituras na parte inferior de cada planta (abaixo do dossel) entre $11 \mathrm{~h} 00$ e $13 \mathrm{~h} 00$; o número total de frutos por planta (NFT), mediante contagem, e a frutificação efetiva (FE - \%) avaliada nos dois lados da planta, selecionando-se aleatoriamente dois galhos grandes (com mais de 100 botões florais), com base na contagem do número de botões ou flores existentes e avaliação da porcentagem de frutificação efetiva aos 50 dias após a polinização. $\mathrm{Na}$ colheita, foram escolhidos aleatoriamente 20 frutos por planta nos quais foram mensurados: diâmetro do fruto (DIA - cm), medido em dois lados da parte equatorial do fruto; comprimento do fruto (COMP - $\mathrm{cm}$ ); o peso total do fruto (g), peso da casca (g) e peso da polpa (g), com o auxílio de balança de precisão (Digimed NX 2000). Posteriormente, o rendimento da polpa (\%) foi estimado pela fração do peso da polpa em relação ao peso total do fruto. Para a extração do suco, foi separada a casca e determinado o valor de $\mathrm{pH}$ ( $\mathrm{pHmetro}$ de bancada); sólidos solúveis totais (SST, `Brix) foram medidos com o auxílio de um refratômetro portátil digital. Também foi determinada a acidez titulável (AT, \% ácido cítrico) pela titulação com $\mathrm{NaOH}$ a $0,1 \mathrm{~N}$, até $\mathrm{pH}=8,2$. Determinouse a relação entre os sólidos solúveis totais e a acidez titulável (SST/AT).

Os dados foram submetidos à análise de variância (ANOVA) considerandose um esquema fatorial $2 \times 2$ ( 2 podas e 2 cultivares), inteiramente casualizado. Para as variáveis que os pressupostos de homocedasticidade e normalidade não foram atendidos, os dados foram transformados pela raiz quadrada. Foi empregado o programa estatístico $R$ ( $R$ Core Team, 2018).

As plantas $\mathrm{CP}$ registraram diâmetros de caules menores $(11,7 \mathrm{~cm})$ em comparação com as SP $(14,3 \mathrm{~cm})$. Entre as safras 2016/17 e 2017/18, observa-se um incremento do $1,7 \mathrm{~cm}$ no diâmetro do caule (Tabela 1). No diâmetro de copa, o cv. Alcântara $(346 \mathrm{~cm})$ apresentou COP superior ao Nonante $(320 \mathrm{~cm})$ assim como as plantas sem poda apresentaram uma maior copa $(357 \mathrm{~cm})$ em relação às podadas. Maiores alturas de plantas ocorreram em plantas SP, no cV. Alcântara (Tabela 1).

As plantas CP apresentaram um menor IAF $\left(1,9 \mathrm{~m}^{2} / \mathrm{m}^{2}\right)$ em comparação com as plantas SP $\left(3,8 \mathrm{~m}^{2} / \mathrm{m}^{2}\right)$. Entre as safras 2016/17 e 2017/18, as plantas incrementaram $1,1 \mathrm{~m}^{2} / \mathrm{m}^{2}$ no IAF (Tabela 1). Isto provavelmente tenha relação com o dossel da planta e a capacidade que tenha de recuperar-se de uma intervenção exógena, permitindo alta efetividade na absorção de luz e $\mathrm{CO}_{2}$ pelas folhas, e provavelmente porque o IAF está próximo do ideal para expressar seu potencial produtivo. Segundo Martínez-Veja et al. (2008), a radiação incidente na planta de goiabeira-serrana se vê diminuída à medida que se aprofunda no dossel da planta, como consequência da sombra que produzem as folhas e galhos.

O número de frutos foi maior no cv. Alcântara. Foi também verificado que as plantas SP tiveram o maior número de frutos (462 frutos), enquanto as plantas CP registraram em média 266 frutos. Provavelmente, isso aconteceu porque as plantas sem poda permaneceram com mais ramos, inclusive mais ramos florais, além de maior IAF.

A frutificação efetiva, resultante da polinização natural, foi maior nas plantas CP (21,9\%) que nas SP $(13,8 \%)$. Esta frutificação efetiva foi menor que a observada por Finatto et al. (2011) em acessos autoincompatíveis (38\%) e autocompatíveis (57\%) sob polinização natural. Na Colômbia árvores sem poda mostraram médias significativamente menores no número de botões florais, comparadas com as árvores onde tenha sido realizada a poda e o arqueamento (entre $45^{\circ}$ e $90^{\circ}$ ) de abertura dos ramos (ortopedia) (QUINTERO, 1993). Segundo este autor, a poda e a ortopedia culminam com a emissão de um número maior de botões florais e também com número consideravelmente maior de flores, assim como diferenças no tempo de colheitas. A poda e a ortopedia ainda se constituem em um fator importante no planejamento de picos de produção de um pomar (QUINTERO, 1993).

$\mathrm{O}$ cv. Nonante apresentou os maiores diâmetro e peso do fruto em comparação ao cv. Alcântara. A poda proporcionou frutos com os maiores diâmetros, comprimento e peso. A interação significativa entre os fatores Cultivar e Poda $(P<0,05)$ foi em decorrência de que o cv. Nonante obteve maior incremento no tamanho dos frutos pelos efeitos da poda, em comparação com o cv. Alcântara. As plantas podadas produziram seus frutos com comprimento similar nas duas safras, enquanto as plantas sem poda incrementaram o comprimento do fruto na safra 2017/18 comparativamente à safra anterior. Este» 
Tabela 1. Diâmetro de caule (CAU), diâmetro de copa (COP), altura de planta (ALT), índice de área foliar (IAF), número total de frutos por planta (NFT), frutificação efetiva (FE), diâmetro do fruto (DIA), comprimento do fruto (COMP), peso do fruto (PESO), rendimento de polpa (POLPA), sólidos solúveis totais (SST), acidez titulável (AT) e pH nos tratamentos sem poda (SP) e com poda (CP) nos cultivares de goiabeiraserrana Alcântara e Nonante. EPAGRI, durante os ciclos produtivos 2016/17 e 2017/18, São Joaquim, SC, 2018 Table 1. Diameter of stem (CAU), diameter of canopy (COP), height of plant (ALT), leaf area index (LAI), total fruit number per plant (NFT), fruit set (FE), diameter of fruit (DIA), length of fruit (COMP), total weight (PESO), yield of pulp (POLPA), total soluble solids (SST), titratable acidity (AT) and $\mathrm{pH}$ in the treatments without pruning (SP) and with pruning $(C P)$ in the feijoa Alcântara and Nonante cultivars, during 2016/17 and 2017/18 harvest, São Joaquim, SC, 2018

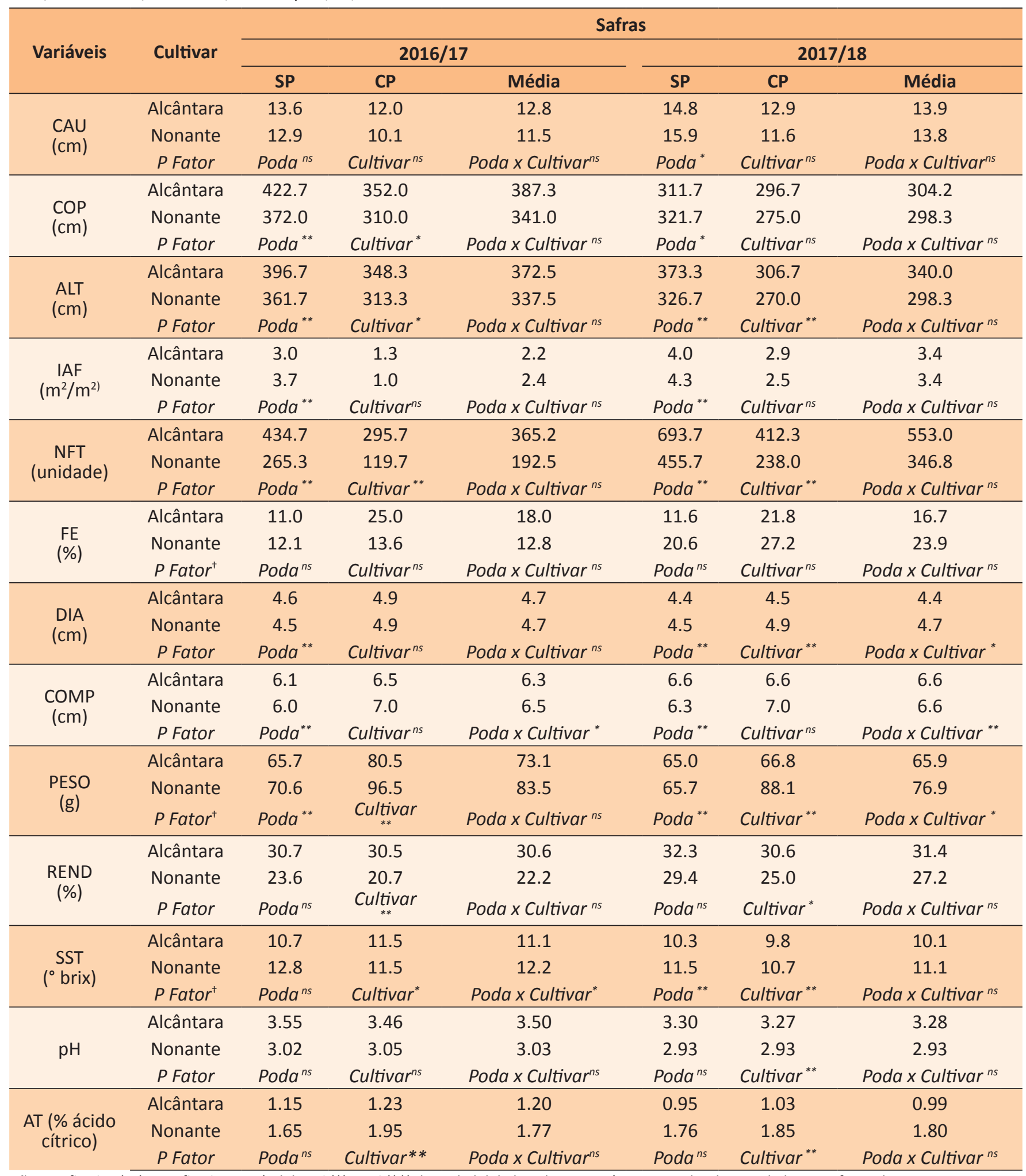

Não significativo (ns); Significativo ao nível de $5 \%\left({ }^{*}\right)$ e $1 \%\left({ }^{* *}\right)$ de probabilidade pelo teste $\mathrm{F}$. + ANOVA realizado com dados transformados com a raiz quadrada dos valores primários. 
comportamento da variação em número, tamanho e peso de frutos ocorre porque está correlacionado com o peso total e o rendimento de polpa dos frutos (DONAZZOLO et al., 2017). Além disso, a planta podada distribui melhor os fotoassimilados tendendo a ter um fruto de maior tamanho. $\mathrm{Na}$ avaliação da posição de fruto na planta, Martínez-Veja et al. (2008) encontraram que frutos com maior peso fresco foram registrados onde as plantas receberam maior radiação.

Por outro lado, embora as plantas com poda tenham apresentado menor número de frutos, estes tiveram maior diâmetro, comprimento e peso em comparação às plantas sem poda. Assim, o peso por fruto aumentou $12,7 \%$ com a poda no cv. Alcântara, e aproximadamente $35,4 \%$ no cv. Nonante. O aumento do peso médio dos frutos está relacionado com o número de frutos produzidos por planta; assim sendo, a maior quantidade de frutos na planta pode induzi-la a produzir frutos menores em peso e tamanho.

A diferença no rendimento de polpa somente foi significativa $(P<0,01)$ entre os cultivares, sendo o cv. Alcântara aquele que registrou o maior rendimento (31\%). Os valores de SST e AT foram maiores no cv. Nonante, enquanto o pH do fruto foi maior no cv. Alcântara. A interação significativa entre os fatores estudados $(P<0,05)$ também é explicada pelo teor de SST, que na safra 2016/17 aumentou nas plantas podadas do cv. Alcântara, enquanto no cv. Nonante diminuiu. Possivelmente outros fatores como, por exemplo, temperatura, inso- lação e umidade, os quais influenciam a fotossíntese da planta, tenham também influenciado esse parâmetro. A acidez titulável e o pH do suco não diferiram em função da aplicação ou não da poda. Em pessegueiros as variações de época de poda também não alteraram as características físico-químicas de $\mathrm{pH}, \mathrm{SST}$, AT e SST/AT (GONÇALVES et al., 2014).

De uma forma geral a realização da poda nos dois cultivares de goiabeiraserrana influencia especialmente a altura das plantas, e incrementa parâmetros relacionados ao rendimento de frutos, demonstrando ser uma prática importante no cultivo comercial desta espécie. Em termos de qualidade do fruto, o teor de SST pode aumentar com a poda. Por fim, é importante ressaltar que as características de frutos de genótipos distintos respondem diferentemente à poda.

\section{Referências}

DONAZZOLO, J.; SALLA, V.P.; SASSO, S.A.Z.; DANNER, M.A.; CITADIN, I.; NODARI, R.O. Path analysis for selection of feijoa with greater pulp weight. Ciência Rural, Santa Maria, v.47, n.6, e20161062, 2017.

DUCROQUET, J.P.H.J.; HICKEL, E.R.; NODARI, R.O. Goiabeira serrana (Feijoa sellowiana). Jaboticabal: FUNEP, Série Frutas nativas, 5. 66p. 2000.

FINATTO, T.; SANTOS, K.L.; STEINER, N.; BIZZOCCHI, L.; HOLDERBAUM, D.F.; DUCROQUET, J.P.; GUERRA, M.P.; NODARI, R.O. Late-acting self-incompatibility in Acca sellowiana (Myrtaceae). Australian Journal of Botany, v.59, n.1, p.53-60, 2011
GONÇALVES, M. A.; COCCO, C.; VIGNOLO, G. K.; PICOLOTTO, L. Efeito da intensidade de poda na produção e qualidade de frutos de pessegueiro. Revista Brasileira de Fruticultura, v.36, n.3, p.742- 747, 2014

MARTÍNEZ-VEGA, R.R.; FISCHER, G.; HERRERA, A.; CHAVES, B.; QUINTERO, O.C. Características físico-químicas de frutos de feijoa influenciadas por la posición en el canopi. Revista Colombiana de Ciencias Hortícolas, Bogotá, v.2, n.1, p.21-32, 2008

NETO, C.K.; SILVA, M.; PORTO, A.H.; AIRES, N.M.V.; WAGNER JÚNIOR, A.; TARTAS, P.L. Intensidade e época de poda em araçazeiro amarelo (Psidium cattleyanum) cv. Ya-Cy após as geadas da estação. Cadernos de Agroecologia. Anais do VI CLAA, X CBA e V SEMDF - v. 13, n. 1, 6p. 2018.

QUINTERO, C.O. Control de cosechas empleando nuevas técnicas de poda en germoplasma y cultivares de feijoa Acca sellowiana. Revista Agro-Desarrollo, Bogotá, v.4, n.1-2, p.89-103, 1993.

QUINTERO, C.O. Selección de cultivares, manejo del cultivo e regulación de cosechas de feijoa. In: FISCHER, G.; MIRANDA, L.D.; CAYÓN, S.G.; MAZORRA, A.M. (ed). Cultivo, poscosecha y exportación de la feijoa (Acca sellowiana Berg). Produmedios. Bogota, CO. p. 49-72. 2003.

TEAM, R. Core. R: A language and environment for statistical computing. Vienna, Austria. URL https://www.R-project.org/. 2018.

RAMOS, D.P.; LEONEL, S.; DA SILVA, A.C.; DE SOUZA, M.E.; DE SOUZA, A.P.; FRAGOSO, A.M. Épocas de poda na sazonalidade, produção e qualidade dos frutos da goiabeira 'Paluma'. Semina: Ciências Agrárias, Londrina, v.32, n.3, p.909-918, 2011. 